\title{
1 Sense and non-sense of shear reloaded
}

2

3 Bernhard Grasemann ${ }^{1}$, Marcin Dabrowski ${ }^{2,3}$, Martin P.J. Schöpfer ${ }^{1}$

$4 \quad{ }^{1}$ Department for Geodynamics and Sedimentology, University of Vienna, Austria (Bernhard.Grasemann@univie.ac.at)

$5{ }^{2}$ Computational Geology Laboratory, Polish Geological Institute - National Research Institute, Wroclaw, Poland

$6{ }^{3}$ Physics of Geological Processes (PGP), The NJORD Centre, , University of Oslo, Norway

\section{Abstract}

9 This paper reviews the geometrical and mechanical evolution of selected groups of kinematic indicators

10 that are frequently used for inferring large-scale geodynamics but are prone to ambiguous shear sense

11 interpretations: (i) Flanking folds and shear bands are complex structures because under general shear conditions co-rotating secondary shear zones can experience either syn- or antithetic slip leading to extensional or contractional offsets. On the other hand, counter-rotating secondary shear zones can exhibit either extensional or contractional offsets but always experience synthetic slip. (ii) Boudinaged layers may display both syn- and antithetic offset across the interboudin surfaces. In addition to the flow type, the initial orientation of interboudin surfaces strongly influences the sense of slip. Under coaxial flow conditions and with high-strength contrast between the boudinaged layer and the matrix, domains of layer-oblique parallel interboudin surfaces can form by chance and their local occurrence may hence lead to misinterpretations of shear zone kinematics, in particular if the number of observable boudins is small. If the viscosity contrast between the boudinaged layer and the matrix is low, domino boudins may strongly deform internally during shearing so that, in contrast to flanking structures, antithetic slip along interboudin surface may lead to a marked normal drag, resulting in shear band boudinage geometries that appear to have formed during flow with an opposite shear sense. (iii) Winged inclusions are pinchand-swell shaped objects rotating into the shear direction. After several revolutions, these structures can resemble $\sigma_{b}$-type clasts or clasts with stair stepping that formed during shear flow with the opposite shear sense. In this paper, new and published examples of these ambiguous shear sense indicators are discussed and interpreted. We give some guidelines for the correct interpretation of these structures with the caveat that if marker lines and their deflections are not well-preserved these shear sense criteria are not always reliable kinematic indicators. 
One of the major aim in tectonic studies is to derive the progressive kinematic history recorded in sheared rocks, in particular when these rocks define boundaries between different tectonometamorphic units. Before the launch of the Journal of Structural Geology in 1979, kinematic interpretations of faults and shear zones in structural geology textbooks were mainly restricted to offset marker horizons and fold vergence (Turner and Weiss, 1963; de Sitter, 1964; Billings, 1972; Hills, 1972). With notable exceptions, kinematic interpretations in these textbooks focused on tension and shear fractures in brittle faults (Hills, 1972), oblique fabrics (Sander, 1950), or rotated minerals in sheared metamorphic rocks (Fairbairn, 1949).

As the interest in physical concepts of flow and progressive deformation in structural geology increased (e.g. Elliot, 1972; Ramberg, 1975; Ghosh and Ramberg, 1976; Means et al., 1980; Lister and Williams, 1979; Passchier, 1986, 1988), several new kinematic indicators were described and summarized in seminal review papers on shear sense indicators in brittle and ductile rocks (Petit, 1987; Passchier and Simpson, 1986; White et al., 1986, Hanmer and Passchier, 1991). Quantitative measurements of orientations and finite strain preserved in structures with monoclinic symmetry were used to derive the kinematic vorticity number (for a review see Xypolias, 2010 and references cited therein), which is a measure of the ratio of the pure and simple shear component of the flow (Means et al., 1980). Modern structural geology textbooks provide comprehensive overviews of kinematic indicators in brittle faults and ductile shear zones (e.g. Blenkinsop, 2000; van der Pluijm and Marshak, 2004; Passchier and Trouw, 2005; Twiss and Moores, 2007; Fossen, 2016), giving the impression that the interpretation of the "shear sense" is straightforward and well understood.

However, detailed field observations (e.g. Simpson and Schmid, 1983; Behrmann, 1987; Hanmer and Passchier, 1991; Passchier and Williams, 1996) and in particular results of analytical and numerical models (e.g. Mandal et al., 2000a; Passchier and Druguet, 2002; Samanta et al., 2002; Schmid and Podladchikov, 2004; Kocher and Mancktelow, 2005; Mulchrone et al., 2005; Wiesmayr and Grasemann, 2005; Jiang, 2007; Fletcher, 2009; Dabrowski and Schmid, 2011; Schmalholz and Maeder, 2012; Dabrowski and Grasemann, 2014; Marques et al., 2014; Grasemann and Dabrowski, 2015; Adamuszek and Dabrowski, 2017; Schöpfer et al., 2017) challenged some of the classical interpretations of structures with monoclinic symmetries because the strain evolution of kinematic indicators can be significantly influenced by numerous factors, such as mechanical interactions, confined flow, slipping interfaces, initial geometrical configurations, composite rheological materials and mechanical anisotropies. In this review, we focus on a selection of frequently used groups of kinematic indicators, in particular flanking 
structures, boudinage and rotating inclusions in ductile shear zones, which may lead to ambiguous interpretations of the shear sense. Our interpretation of these structures is supported by the results of mechanical models, which assist in identifying well-preserved natural examples. The paper concludes with a discussion of selected natural examples, some of which are published but allow alternative interpretations.

\section{Ambiguous shear sense criteria}

\subsection{Flanking structures developed along secondary shear zones}

70 Secondary shear zones known as shear bands, C'-type or extensional crenulation cleavage have been

71 recognized to record important information about the kinematic history of sheared rocks (Berthé et al., 72 1979; White, 1979; Platt and Vissers, 1980). In fact, shear bands are one particular geometry, and various 73 other geometries can develop along cross cutting elements or slip surfaces that localize deformation, 74 leading to a large family of structures collectively called flanking structures (Grasemann and Stüwe, 75 2001; Passchier, 2001). Flanking structures can be classified on the basis of their sense of slip (syn- or antithetic) and their drag geometry (normal or reverse; Wiesmayr and Grasemann, 2005). A non-generic classification based on geometric criteria developed around secondary shear zones has been suggested by Coelho et al. (2005). Under the simplest circumstances, namely two-dimensional uniform general shear of homogenous and anisotropic materials, these secondary shear zones generally have the rotational behaviour of passive marker lines in a homogeneous medium (Kocher and Mancktelow, 2005) and their instantaneous rotation rate, stretch and shear are primarily dependent on their orientation and the kinematic vorticity number of the flow. Figure 1 shows an off-axis Mohr Circle representation of the deformation gradient tensor $F$ (De Paor and Means, 1984) showing the eigenvectors of flow $\left(a_{1,2}\right)$, the angle $\alpha$ between the eigenvectors, the instantaneous stretching axes $\left(I S A_{1,2}\right)$, and the maximum and minimum shear strain rate $\left(\dot{\gamma}_{1,2}\right)$. The lower right $\left(F_{11}, F_{21}\right)$ and the upper left coordinates $\left(F_{12}, F_{22}\right)$ of the deformed unit square correspond to the components of $F$. If there is no shear component perpendicular

87 to the base of the unit square (i.e. $F_{21}=0$ ) the kinematic vorticity number $W_{k}$ (e.g. Means et al., 1980),

88 which is the cosine of $\alpha$, can be simply expressed by the components of $F$ by

$89 \quad W_{k}=\frac{1}{\sqrt{\left(\frac{F_{11}-F_{22}}{F_{12}}\right)^{2}+1}}$. 
Under simple shear all material lines rotate into the shear direction (Fig. 1a), but under general shear (Fig. 1b) counter-rotation also occurs, resulting in six different behavioural fields for secondary finite shear zones (Grasemann et al., 2003): Co-rotating shear zones can either experience synthetic slip/shortening (+I), antithetic slip/shortening (+II), antithetic slip/stretching (+III), or synthetic slip/stretching (+IV). Counter-rotating material lines can only experience synthetic slip and are either shortening (-I) or stretching (-II). For geometrical reasons, a central marker line offset by the secondary shear zone will always exhibit reverse drag (Coelho et al., 2005) that may be superposed by normal drag (Grasemann et al., 2005), resulting in a number of instantaneous flanking structure geometries that may record approximate mirror symmetries between the end-member deformations of pure shear transtension, simple shear and pure shear transpression (Wiesmayr and Grasemann, 2005). The progressive development of flanking structures during large strain deformation is even more complex since the secondary shear zone might rotate through the different fields and hence can switch slip from syn- to antithetic and back to synthetic (Exner et al., 2004, Kocher and Mancktelow, 2005; see movie in DR 1). In general shear transpression and transtension, under which secondary shear zones might also experience back-rotation, similar mirror-imaged structures may develop hampering their kinematic interpretation (Wiesmayr and Grasemann, 2005). For example, synthetic shear bands with a central marker line exhibiting reverse drag resemble mirror images of extensional flanking structures that developed along antithetic secondary shear zones (compare Fig. 2a and b). Similarly, flanking structures exhibiting contractional offset of a central marker along an antithetic secondary shear zone mimic the mirror symmetry of structures formed along synthetic secondary shear zones (compare Fig. 2c and d). However, a closer inspection of Figure 2 provides clues that help discriminating these structures, a task that is attainable when the inspected natural example shows clearly visible marker lines:

Under general shear, synthetic shear bands develop parallel to the shortening flow eigenvector (Fig. 2a) and do not rotate into the shear direction. During ongoing deformation the shear bands accumulate synthetic slip that displaces, within the shortening quadrants, the central marker line with increasing shearing towards the secondary shear zone tips, resulting in a marked reverse drag. On the other hand, within the extensional quadrants, the marker lines are deformed to become almost parallel to the secondary shear zone, resulting in a marked normal drag. This change from normal to reverse drag along the secondary shear zone results in peculiar geometries exhibiting marker lines at both zone ends that meet at almost right angles. accumulate an offset as large as synthetic shear bands, because they rotate at some stage (in simple 
shear but also in general shear) into the field where the marker's offset along the secondary shear zones switches from anti- to synthetic. The resulting normal drag in the extensional quadrants of the secondary shear zone may become less pronounced, but the reverse drag in the compressional quadrants is frequently characterized by markers with a prominent hook-shape (Hudleston, 1989) or over-roll (Coelho et al., 2005). In summary, synthetic shear bands and extensional flanking structures developing along antithetic secondary shear zones may be difficult to discriminate except for large offset at the tip of the secondary shear zone, a feature that is however only typical for synthetic shear bands.

In simple shear contractional synthetic and antithetic flanking structures can be distinguished by the acute angle between the secondary shear zone and the shear zone boundary like so: Contractional synthetic flanking structures have acute angles smaller than $45^{\circ}$, whereas contractional antithetic flanking structures have acute angles greater than $45^{\circ}$ (Fig. $2 \mathrm{c}$ and d). However, distinction between these two types of flanking structures is difficult or even impossible under general shear, or when markers are initially oblique to the shear zone boundary, or when the orientation of the shear zone boundary is uncertain (Grasemann and Wiesmayr, 2005).

\subsection{Domino and shear band boudinage}

In monoclinic shear zones layer boudinage can be classified into three end member classes with respect to the bulk shear sense: (i) symmetric boudinage without slip on the inter-boudin surface (no-slip boudinage); (ii) synthetic (shear band) boudinage or (iii) antithetic (domino) boudinage (for more details and subdivisions including the boudin shapes based on more than 2000 natural examples see Goscombe et al., 2004). However, the kinematic interpretation of boudinage is not always straightforward and requires knowledge of the initial orientation of the interboudin surfaces with respect to both the boudinaged layer and the shear zone boundary (Passchier and Druguet, 2002; Goscomb and Passchier, 2003; Mandal et al., 2007). Dependent on elastic properties, strength and mechanical anisotropy of the surrounding material (Strömgård, 1973; Mandal et al., 2000b; Mancktelow, 2008), boudin trains develop interboudin surfaces approximately perpendicular to layering, forming either torn, which are frequently reworked into domino boudinage (Goscombe et al., 2004). Alternatively, boudin trains may develop backward or forward vergent interboudin surfaces with syn- and antithetic slip, resulting in shear band boudinage with mirror symmetries (Goscombe and Passchier, 2003). As a consequence the final boudinage structure is strongly dependent on the initial orientation of the interboudin surfaces with respect to the boudinaged layer. 
Numerical models and natural examples suggest that, besides the symmetric boudinage without slip on the inter-boudin surfaces, also symmetric shear fracture boudinage ("horst and graben 154 structure") with backward- and forward vergent interboudin surfaces may develop, resulting in geometries typically interpreted to have formed under coaxial strain boundary conditions (e.g. Schenk et al., 2007; Abe and Urai, 2011; Schöpfer et al., 2017). A quantitative measure of the relative amount of extension accommodated by oppositely dipping interboudin surfaces is the polarity $(-1 \leq P \leq 1)$, defined as the normalized sum of throw $T$ on left dipping (positive throw) and on right dipping (negative throw) surfaces, i.e. $P=\Sigma T /|\Sigma T|$ (alternatively the signed heave can be taken). Absolute polarity values close to one are hence characteristic for asymmetric boundinage (typically interpreted to have formed under non-coaxial flow), whereas symmetric fracture boudinage yields values of around zero (likely to reflect co-axial flow). Numerical models (see Appendix A.2. for details) of fracture boudinage formation under coaxial boundary conditions revealed however that the 'classical interpretation' of asymmetric shear band boudinage may be incorrect, because parallel layer-oblique interboudin surface can form by chance, in particular when the strength contrast between the boudinaged layer and the surrounding material is high so that the boudins can rotate during progressive deformation (Schöpfer et al, 2017). Figure 3 shows the results of three discrete element method (DEM) models (for model details see Appendix A.2. and Schöpfer et al, 2017) of the formation of fracture boudinage under coaxial strain boundary conditions after $10 \%$ extension. The three results started all with the same initial geometry and identical particle/bond properties, but different random placement of particles, comprising a central brittle layer (with passive markers) embedded in a weak matrix. The local presence of parallel layeroblique interboudin surface may hence not reflect a non-coaxial background flow, in particular when the sample size (e.g., number of boudins) is small, because if the dip direction of the interboudin surfaces is random and independent of the adjacent surfaces, the probability $p$ for $N$ surfaces dipping in the same direction is $p=(1 / 2)^{(N-1)}$ (e.g., there is a $25 \%$ chance for three parallel surfaces; Schöpfer et al, 2017). A simple probability analysis could help to assess whether the number of interboudin surfaces is large enough to draw kinematic conclusions about the polarity of asymmetric boudinage. deformable domino boudins have been compared with a-type flanking folds associated with a reverse drag along the interboudin surface (Grasemann and Stüwe, 2001; Goscomb and Passchier, 2003). Although the process has many similarities with the progressive development of flanking structures, the 
major difference is that the interboudin surface (in contrast to cross-cutting elements of flanking structures) terminates at the intersection between the interboudin surface and the boundary between the boudinaged layer and the host rock. A major consequence of this confined slip along the interboudin surface is a viscosity ratio-dependent rotation and deformation of the boudin segments (Dabrowski and Grasemann, 2014). High viscosity ratios between the boudinaged layer and the host rock result in rotation and tilting of almost rigid boudin segments, leading to bookshelf or domino boudinage (Ramsay and Huber, 1987; Hanmer and Passchier, 1991). However, low viscosity ratios lead to rotation of both the interboudin surface and the boudin block into the shear direction at different rates and strong internal deformation of the individual boudin blocks. Figure 4 shows a numerical model (see Appendix A.3. for model details) of the progressive formation of deformable domino boudins with periodic velocity boundary conditions corresponding to an almost ideal dextral simple shear (a small amount of layerparallel extension is used to facilitate rotation of the boudin segments). The pre-defined aspect ratio of the boudins is three and the initial interboudin surface is perpendicular to layering. Because this process has many similarities with the formation of extensional antithetic flanking structures (compare with field +III in Figs. 1 and 2b), which are associated with a marked reverse drag of central marker lines, several studies on boudinage and flanking structures speculated that deformable domino boudinage may also develop reverse drag of internal markers within the boudins (e.g. Grasemann and Stüwe, 1999; Passchier and Druguet, 2002; Goscomb et al., 2004). Interestingly, our numerical model demonstrates that mechanical layering has a strong influence on drag development along the interboudin surface and, contrary to the expectation of previous studies, a marked normal drag develops within the boudins along the interboudin surfaces, whereas reverse drag is only confined to the edge, where the interboudin surface is in contact with the matrix (as highlighted by the arrow in Fig. 4c). Importantly, this marked normal drag within the boudins along the antithetic and co-rotating interboudin surfaces resembles boudin geometries that are mirror-symmetric to shear band boudinage developing under shear flow with the opposite directions. In natural rocks, shear band boudins might be very difficult to discriminate from deformable bookshelf boudins and should not be used as independent kinematic indicators without constraints from other shear sense criteria.

\subsection{Winged inclusions}

Numerous studies have investigated the mechanical behaviour of inclusions such as porphyroclasts in deformed rocks because they provide important information about the rheology, the properties of the inclusion-matrix interface, the finite deformation and the flow kinematics (e.g. Mancktelow 2013; Marques et al., 2014 and references cited therein). Such inclusions comprise single crystals (naked clasts, 
mineral fish), porphyroclast systems (mantled porphyroclasts, porphyroclasts with reaction rims or strain shadows), sigmoids (polycrystals) or winged inclusions, which are in general inclusions revealing a pinchand-swell geometry (Hanmer and Passchier, 1991; Passchier and Trouw, 2005). Dependent on a number of possibly time-dependent factors, like mantle thickness, initial clast shape and orientation, clast-matrix coupling, the clast-rim-matrix system's rheology, flow vorticity and finite strain, the porphyroclast systems can develop $\sigma$-type or $\delta$-type shapes with monoclinic symmetry that can serve as shear sense indicators. $\sigma$-type inclusions can be furthermore classified into $\sigma_{a}$ - and $\sigma_{b}$-types, with wings parallel to the shear plane and to the synthetic shear bands, respectively (Passchier and Simpson, 1986).

Reworking of an isolated pinch-and-swell object by shear flow leads to the formation of a winged inclusion (Hanmer, 1990). In contrast to $\sigma_{\mathrm{a}}$ - and $\sigma_{\mathrm{b}}$-types clasts, where the wings develop a fixed position on both sides of the clast and only the core is rotating, both the core and the wings of winged inclusions rotate, although at different rates (Grasemann and Dabrowski, 2015). After the elongated core of winged inclusions has rotated out of the shear plane to an inclined orientation, with the long axis of the elongated core dipping shallowly into the shear direction (Fig. 5b), the resulting geometry can be easily confused with $\sigma_{b}$-type clasts developing under an oppositely directed shear flow. With the wing ends still attached to the central reference line the inclusions resemble the geometries of $\sigma_{b}$-type clasts, whose wings are however oriented in a c'-orientation with an opposite shear sense. With further rotation (Fig. $5 \mathrm{~d})$, the wings rotate out of the central reference line resembling a stair-stepping geometry that would yield the opposite shear sense if 'classically interpreted' (Passchier and Trouw, 2005). After a $180^{\circ}$ rotation of the core of the object, the wings, which rotate slower than the core, are stretched but still inclined at a small angle against the shear direction (Fig. 5e). Clearly, $\sigma_{b}$-type clasts are difficult to distinguish from winged inclusions developing under an opposite shear flow, in particular when the orientation of the central reference line is not exactly known. However, a closer inspection of the coupling between the clast and the matrix (Schmid and Podladchikov, 2005) and the presence of strongly recrystallized material in the wings might help to distinguish between $\sigma_{b}$-type clast (decoupled) and winged inclusions (coupled).

\section{Discussion}

\subsection{Interpretation of selected natural examples.}

The structure shown in Figure 6a formed in Middle Cretaceous clay-rich limestones of the Nahr Umr Formation (Jabal Akhdar dome, Oman; picture courtesy of A. Grobe). A classical kinematic interpretation of the structure would most likely yield shear band (foliation) boudinage with a top-to-the SW shear 
sense. However, the overall shear sense is top-to-the NE, a sense confirmed by both regional tectonics and other independent shear sense criteria (Grobe et al., in press). A closer inspection reveals that the central marker layer (black solid line in Fig. 6a) exhibits normal drag along the cross-cutting elements represented by secondary shear zones (orange dotted lines in Fig. 6a). With reference to the numerically modelled geometry shown in Figure 4, we suggest that this structure developed as a deformable domino boudinage within a layer having a low competence contrast with the host rocks, followed by subsequent rotation of the interboudin surfaces into the shear directions producing antithetic slip but normal drag.

Figure $6 \mathrm{~b}$ shows a polished slab from a loose marble mylonite block collected from the Brenner Mesozoic of the Ötztal-Bundschuh Nappe System (Eastern Alps, Austria). The mylonites define a nappe boundary and are thought to have formed during Cretaceous exhumation with a consistent top-to-the ESE shear sense (Fügenschuh et al., 1997). Although it is tempting to interpret the structure as an asymmetric shear band boudinage recording a top-to-the left shear sense, the sample has been sheared top-to-the right, consistent with $\mathrm{mm}$-sized mica-fish within impure layers located at the bottom, within and on top of the boudinaged layer (arrows in Fig. 6b). In fact the structure can be best explained by early brittle fractures that later developed into antithetic secondary shear zones during rotation into the shear direction forming a system of parallel and conjugate flanking structures (Exner et al., 2006). Faults dipping steeply into the shear direction were probably not rotated and hence record very little offset. On the other hand, secondary shear zones with up to c. $1 \mathrm{~cm}$ antithetic offset rotated into the shear direction. Note that the displacement profiles of the shear zones are rather flat (e.g., the displacement is constant along zones labelled $d_{1}$ and $d_{2}$ in Fig. $6 b$ ) with high displacement gradients being restricted to near the tips of shear zones, which sole into a phyllosilicate-rich layer within which displacement is accommodated by contiguous sliding. This displacement transfer could explain the minor drag of marker lines along the shear zones. This example illustrates that, although isolated flanking structures are quite ambiguous shear sense criteria, a system of conjugate flanking structures exhibiting a triclinic symmetry can unequivocally record the flow kinematics when carefully inspected.

272

Figure $6 c$ shows conglomeratic calcschists of the Glockner-Nappe System (Wasserfallwinkel, 273 Großglockner). The deformed marble pebble exhibits well-developed wings with stair stepping, 274 suggesting a top-to-the SSE shear sense. However, regional structural observations (Kurz et al., 1996) 275 and SC-fabrics defined by shape preferred orientations of calcite grains observed at local outcrops indicate an overall top-to-the NNW shear sense. We therefore propose that the structure is a winged

277 inclusion that formed by co-rotation of an elongated marble clast revolving by at least $180^{\circ}$ so that the 278 kinematics is consistent with a top-to-the NNW shear sense. A comparison of this structure with 
numerical modelling results (see Fig. 5e and Grasemann and Dabrowski, 2015) suggests that a core rotation together with a switch of the right- and left-side wing is indicative of a high shear strain of $\gamma>20$ (compare with Fig. 5e).

The flanking structure shown in Figure $6 \mathrm{~d}$ is from an impure marble mylonite (N Kea, Greece). Marker lines (black solid lines) exhibit a marked change from reverse to normal drag along a secondary shear zone (red dotted line). This structure could be either interpreted as an antithetic flanking fold or as a synthetic shear band, which would be consistent with the overall top-to-the SW shear sense observed elsewhere. Comparison of the natural structure in Figure $6 \mathrm{~d}$ with the modelled geometry shown in Figure $2 \mathrm{a}$ indicates that the structure is indeed a synthetic shear band that developed under top-to-the SW general shear on the basis of the following criteria: (i) A large displacement on the secondary shear zone with marker lines exhibiting normal drag that is almost parallel to the secondary shear zone within the extensional quadrants, where markers of the opposite (compressional) quadrants meet at very high angles. (ii) A central marker line with pronounced normal drag that is not a hook-shape superposed on a reverse drag, a typical feature for antithetic slip on secondary shear zones. (iii) High-angle fractures rotated towards the SW just below the secondary shear zone (white arrows in Fig. 6d).

\subsection{Discussion of selected published examples}

The purpose of this section is a discussion of published kinematic indicators, which can be alternatively interpreted, demonstrating that the examples displayed in Figure 6 are not unique or rare structures developing under exceptional conditions, but are common phenomena in natural sheared rocks. We emphasize that it is not our intention to question the published analysis but to discuss alternative interpretations from the selected references

Ceccato et al. (2017) investigated texture inheritance during mylonitization of quartz veins within the Rieserferner pluton, which underwent deformation during post-magmatic cooling at temperatures of around $450{ }^{\circ} \mathrm{C}$. The authors describe lenticular to fish-shaped ribbon porphyroclasts exhibiting stairstepping geometries climbing against the otherwise well-constrained shear sense, which is opposite to that commonly observed in mica-fish within quartz mylonites (figure 10 in Ceccato et al., 2017). The authors' explanation for the clast geometry is boudinage along micro-shear bands followed by corotation of the ribbon porphyroclasts. Although this model would require that counter-rotation of the clasts during shear-band boudinage is followed by co-rotation, this model is perfectly in line with the development of winged inclusions of isolated lenticular-shaped grains coupled with the very finerecrystallized quartz matrix. The fish-shaped ribbon porphyroclasts of Ceccato et al. (2018) are strikingly 
similar to quartz porphyroclasts with pinch-and-swell geometries from mylonitized quartz veins occurring in the Schober Group in Austria (fig. 3e in Grasemann and Dabrowski, 2015) where the 'nonsense' geometry has been explained by clast rotation into the shear direction resulting in winged inclusions forming under a shear sense consistent with both the texture and the SC fabric within the quartz mylonites (compare Fig. 5b).

In a review paper, Burg (1999) presents geometric and scale-invariant concepts applied to tectonic studies of ductile structures. As an example for anastomosing shear zones in a bulk shear regime, the author shows a spectacular example of an isolated asymmetric boudin within sheared amphibolites of the Bulgarian Rhodope Massif (fig. 12 in Burg, 1999). The boudin has a prominent pinch-and-swell geometry, which is, if the boudin is coupled to the host rock, inherently unstable during shear flow. We propose that the structure could be in fact a winged inclusion (rather than an asymmetric boudin) on the basis of the following two key observations, which can be explained by the core's rotation and host rock coupling (compare Fig. 5b and fig. 9 in Grasemann and Dabrowski, 2015): (i) Strain localization in the form of shear zones along the shortening quadrants of the object and the attached wings and (ii) folding in close vicinity of the object's core in the extensional quadrants. The kinematic direction of the flow suggested by the winged inclusion interpretation is furthermore supported by veins, which have been boudinaged and rotated into the shear direction (lower right part of fig. 12 in Burg, 1999).

Following the collision of India and Asia, the subducted High Himalayan Crystalline extruded in Miocene times between the Main Central Thrust at the base and the South Tibetan Detachment system at the top (e.g. Hodges et al., 1996). Finch et al. (2014) investigated in detail the timing of shear sense reversal at the top of the High Himalayan Crystalline and propose that mafic lithons within a migmatic orthogneiss preserve reverse shearing. Their figure 5D shows K-feldspar porphyroblasts with asymmetric tails resembling, at a first glance, $\sigma_{b}$-type clasts. This interpretation would however require either a backrotation of the clast, probably associated with decoupling of the clast-matrix system (Mancktelow et al., 2002) or wing development along a C'-plane or synthetic shear band orientation (Passchier and Simpson, 1986). An alternative interpretation is that the structures represent winged inclusions that rotated into the shear direction with a normal shear sense at the top of the High Himalayan Crystalline (compare with Fig. 5c). This interpretation is in fact consistent with several $\sigma_{\mathrm{a}}$-type clasts exhibiting clear stair stepping, as shown in figure 5D of Finch et al. (2014).

Syros Island is part of the Cycladic blueschist belt (Greece) and experienced an Eocene highpressure metamorphism followed by an Oligocene/Miocene greenschist facies event. Various kinematic 
341 interpretations, derived from different outcrops, but mainly on the basis of asymmetric boudinage, exist 342 in the literature for both events with a clear predominance of top-to-the E to NE directed shearing (see 343 Laurent et al., 2016 and references cited therein). On the basis of microstructures and several macroscopic shear sense criteria, such as shear band boudinage and sigmoids with clear stair stepping geometries in dolomite layers, Rogowitz et al. (2015) suggest a top-to-the W shear sense for the Eocene event in some western parts of Syros. In contrast, Bond et al. (2007) report for the same outcrops a topto-the $E$ shear sense based on boudinaged dolomite layers with monoclinic symmetries. However, their described structure could also represent a sheared domino boudinage with low viscosity ratio (compare their figure 5e with the numerical results shown in Fig. 4b), which would make it consistent with a topto-the W shear sense, as suggested by Rogowitz et al. (2015). An additional indicator for a low viscosity ratio between the dolomite layers and the calcite host rock during deformation is pinch-and-swelling and fish-mouth boudinage of dolomite layers (fig. 5e in Bond et al., 2007). Further, Bond et al. (2007) point out that both (asymmetric) shear band boudinage and symmetric boudinage with orthorhombic symmetry occur in the same outcrop (their figure 5e). This conundrum could be solved if the shear band boudinage in the dolomite layer is interpreted as a set of fractures that developed a preferred orientation 'by chance' under local coaxial flow conditions (see Fig. 3 and Schöpfer et al. 2017).

The internal zone of the Hellenides is generally considered to correlate with the Attic-Cycladic metamorphic complex. Scheffer et al. (2016) investigated the syn- to post-orogenic western border of the Attic-Cycladic metamorphic complex and concluded that the dominant top-to-the SSW and the local top-to-the NNE shear sense are consistent with the area's location at the junction between the bivergent North and West Cycladic Detachments systems. Their figure $7 \mathrm{~b}$ shows a calcite marble with a mylonitic foliation wrapping around an ellipsoidal dolomite clast. Decoupling of the dolomite from the matrix calcite and back-rotation of the clast into a stable position with the long axis inclined against the shear directions would support the suggested local top-to-the NNE shear sense. An alternative, and in our view more plausible, explanation for this 'non-sense' geometry however is instability of an ellipsoidal clast with a strong matrix coupling and co-rotation out of the shear plane (compare with Fig. 5b and d), so that the structure is consistent with the dominant top-to-the SSW shear sense reported elsewhere in the area (Scheffer et al., 2016).

\section{Conclusions}

We have shown that there is a range of structures that 'mimic' well-established kinematic indicators with 371 the opposite shear sense, which may result, when 'classically interpreted', in wrong kinematic 
interpretations. In particular the rotation of and slip on secondary shear zones and interboudin surfaces of boudinaged layers with low-competence contrast result in structures that have to be interpreted cautiously, especially if the deformation was under general shear flow. Furthermore, the rotation of pinch-and-swell objects may result in geometries that are similar but mirror shapes of $\sigma$-type clasts or sigmoids. We do not question the general applicability and success of classical interpretations of these kinematic indicators, especially when the interpretations are conclusive and tested independently by different criteria. However, shear sense observations that are in conflict with regional observations should be carefully investigated and tested with mechanical models before local observations are extrapolated to large-scale tectonics.

\section{Acknowledgement}

Fruitful discussions with C. Scheffer, J. Urai, A. Ceccato, A.H.N. Rice, A. Rogowitz and J. White are gratefully acknowledged. A big thank you to A. Grobe for providing the picture and important background information of Figure 6a. We thank the Austrian Academy of Sciences (Emil Suess-Erbschaft) for financial support for field work. Editorial handling of the manuscript by Cees Passchier is gratefully acknowledged. The manuscript was improved by constructive reviews by Stefan Schmalholz and an anonymous reviewer.

\section{References} 29, 356-362.

Behrmann, J.H., 1987. A precautionary note on shear bands as kinematic indicators. J. Struct. Geol. 9, 394 659-666.

Berthé, D., Choukroune, P., Jegouzo, P., 1979. Orthogneiss, mylonite and non coaxial deformation of granites: the example of the South Armorican shear zone. J. Struct. Geol. 1, 31-43.

Billings, M.P., 1972. Structural Geology, 3rd ed. ed. Prentice-Hall, Englewood Cliffs, NJ, 606 pp. 
402

403

404

405

406

407

408

409

410

411

412

413

414

415

416

417

418

419

420

421

422

423

Burg, J.-P., 1999. Ductile structures and instabilities: their implication for Variscan tectonics in the Ardennes. Tectonophysics 309, 1-25.

Ceccato, A., Pennacchioni, G., Menegon, L., Bestmann, M., 2017. Crystallographic control and texture inheritance during mylonitization of coarse grained quartz veins. Lithos 290-291, 210-227.

Coelho, S., Passchier, C., Grasemann, B., 2005. Geometric description of flanking structures. J. Struct. Geol. 27, 597-606.

Dabrowski, M., Krotkiewski, M., Schmid, D.W., 2008. MILAMIN: MATLAB-based finite element method solver for large problems. Geochem. Geophys. Geosyst. 9, Q04030, doi:10.1029/2007GC001719

Dabrowski, M., Schmid, D.W., 2011. A rigid circular inclusion in an anisotropic host subject to simple shear. J. Struct. Geol. 33, 1169-1177.

Dabrowski, M., Grasemann, B., 2014. Domino boudinage under layer-parallel simple shear. J. Struct. Geol. 68, Part A, 58-65.

De Paor, D.G., Means, W.D., 1984. Mohr circles of the First and Second Kind and their use to represent tensor operations. J. Struct. Geol. 6, 693-701.

de Sitter, L.U., 1964. Structural geology, 2nd Edition ed. McGraw-Hill Inc., New York, 551 pp.

Elliott, D., 1972. Deformation Paths in Structural Geology. Geol. Soc. Am. Bull. 83, 2621-2638.

Eshelby, J.D., 1959. The elastic field outside an ellipsoidal inclusion. Proc. Royal Soc. A, 252 561-569.

Exner, U., Mancktelow, N.S., Grasemann, B., 2004. Progressive development of s-type flanking folds in simple shear. J. Struct. Geol. 26, 2191-2201.

Exner, U., Grasemann, B., Mancktelow, N.S., 2006. Multiple faults in ductile simple shear: analogue models of flanking structure systems. Geol. Soc. Lond., Special Publications 253, 381-395.

Exner, U., Dabrowski, M., 2010. Monoclinic and triclinic 3D flanking structures around elliptical cracks. J. Struct. Geol. 32, 2009-2021.

Fairbairn, H.W., 1949. Structural petrology of deformed rocks, 2nd edition ed. Addison-Wesley Press Inc., Cambridge, $344 \mathrm{pp}$.

Finch, M., Hasalová, P., Weinberg, R.F., Fanning, C.M., 2014. Switch from thrusting to normal shearing in the Zanskar shear zone, NW Himalaya: Implications for channel flow. Geol. Soc. Am. Bull. 126, 892-924.

Fletcher, R.C., 2009. Deformable, rigid, and inviscid elliptical inclusions in a homogeneous incompressible anisotropic viscous fluid. J. Struct. Geol. 31, 382-387.

Fossen, H., 2016. Structural Geology, 2nd Edition ed. Cambridge University Press, 524 pp.

Fügenschuh, B., Seward, D., Mancktelow, N., 1997. Exhumation in a convergent orogen: the western Tauern window. Terra Nova 9, 213-217.

Ghosh, S.K., Ramberg, H., 1976. Reorientation of inclusions by combination of pure and simple shear. Tectonophysics 34, 1-70. 
Goscombe, B.D., Passchier, C.W., 2003. Asymmetric boudins as shear sense indicators--an assessment from field data. J. Struct. Geol. 25, 575-589.

Goscombe, B.D., Passchier, C.W., Hand, M., 2004. Boudinage classification: end-member boudin types and modified boudin structures. J. Struct. Geol. 26, 739-763.

Grasemann, B., Stüwe, K., 2001. The development of flanking folds during simple shear and their use as kinematic indicators. J. Struct. Geol. 23, 715-724.

Grasemann, B., Stüwe, K., Vannay, J.-C., 2003. Sense and non-sense of shear in flanking structures. J. Struct. Geol. 25, 19-34.

Grasemann, B., Martel, S., Passchier, C., 2005. Reverse and normal drag along a fault. J. Struct. Geol. 27, 999-1010.

Grasemann, B., Dabrowski, M., 2015. Winged inclusions: Pinch-and-swell objects during high-strain simple shear. J. Struct. Geol. 70, 78-94.

Grobe, A., Virgo, S., von Hagke, C., Urai, J. L., Littke, R., in press. Multiphase structural evolution of a continental margin during obduction orogeny: Insights from the Jebel Akhdar Dome, Oman Mountains. Tectonics.

Hanmer, S., 1990. Natural rotated inclusions in non-ideal shear. Tectonophysics 176, 245-255. Hanmer, S., Passchier, C.W., 1991. Shear sense indicators: a review. Paper - Geol. Surv. Canada 90, 1-71. Hills, E.S., 1972. Elements of Structural Geology. Methuen and Co., London, 502 pp. Hodges, K.V., Parrish, R.R., Searle, M.P., 1996. Tectonic evolution of the central Annapurna Range, Nepalese Himalayas. Tectonics 15, 1264-1291.

Hudleston, P.J., 1989. The association of folds and veins in shear zones. J. Struct. Geol. 11, 949-957. Jiang, D., 2007. Numerical modeling of the motion of rigid ellipsoidal objects in slow viscous flows: A new approach. J. Struct. Geol. 29, 189-200.

Kocher, T., Mancktelow, N.S., 2005. Dynamic reverse modelling of flanking structures: a source of quantitative kinematic information. J. Struct. Geol. 27, 1346-1354

Kurz, W., Neubauer, F., Genser, J., 1996. Kinematics of Penninic nappes (Glockner Nappe and basementcover nappes) in the Tauern Window (Eastern Alps, Austria) during subduction and PenninicAustroalpine collision. Eclogae Geol. Helv. 89, 573-605.

Laurent, V., Jolivet, L., Roche, V., Augier, R., Scaillet, S., Cardello, G.L., 2016. Strain localization in a fossilized subduction channel: Insights from the Cycladic Blueschist Unit (Syros, Greece). Tectonophysics 672-673, 150-169.

Lister, G.S., Williams, P.F., 1979. Fabric development in shear zones: theoretical controls and observed phenomena. J. Struct. Geol. 1, 283-297.

Mancktelow, N.S., Arbaret, L., Pennacchioni, G., 2002. Experimental observations on the effect of interface slip on rotation and stabilisation of rigid particles in simple shear and a comparison with natural mylonites. J. Struct. Geol. 24, 567-585. 
472 Mancktelow, N.S., 2008. Tectonic pressure: Theoretical concepts and modelled examples. Lithos 103, $473 \quad 149-177$.

474 Mancktelow, N.S., 2013. Behaviour of an isolated rimmed elliptical inclusion in 2D slow incompressible 475 viscous flow. J. Struct. Geol. 46, 235-254.

476 Mandal, N., Kumar Samanta, S., Chakraborty, C., 2000a. Progressive development of mantle structures 477 around elongate porphyroclasts: insights from numerical models. J. Struct. Geol. 22, 993-1008.

478 Mandal, N., Chakraborty, C., Samanta, S.K., 2000b. Boudinage in multilayered rocks under layer-normal 479 compression: a theoretical analysis. J. Struct. Geol. 22, 373-382.

480 Mandal, N., Dhar, R., Misra, S., Chakraborty, C., 2007. Use of boudinaged rigid objects as a strain gauge: 481 Insights from analogue and numerical models. J. Struct. Geol. 29, 759-773.

482 Marques, F.O., Mandal, N., Taborda, R., Antunes, J.V., Bose, S., 2014. The behaviour of deformable and 483 non-deformable inclusions in viscous flow. Earth-Sci. Rev. 134, 16-69.

484 Means, W.D., Hobbs, B.E., Lister, G.S., Williams, P.F., 1980. Vorticity and non-coaxiality in progressive 485 deformation. J. Struct. Geol. 2, 371-378.

486 Mulchrone, K.F., Grogan, S., De, P., 2005. The relationship between magmatic tiling, fluid flow and crystal 487 fraction. J. Struct. Geol. 27, 179.

488 Passchier, C.W., 1986. Flow in natural shear zones - the consequences of spinning flow regimes. Earth 489 Planet Sci. Lett. 77, 70-80.

490 Passchier, C.W., Simpson, C., 1986. Porphyroclast systems as kinematic indicators. J. Struct. Geol. 8, 831491844.

492 Passchier, C.W., 1988. Analysis of deformation paths in shear zones. Geol. Rundsch. 77, 309-318.

493 Passchier, C.W., Williams, P.R., 1996. Conflicting shear sense indicators in shear zones; the problem of 494 non-ideal sections. J. Struct. Geol. 18, 1281-1284.

495 Passchier, C.W., 2001. Flanking structures. J. Struct. Geol. 23, 951-962.

496 Passchier, C.W., Druguet, E., 2002. Numerical modelling of asymmetric boudinage. J. Struct. Geol. 24, 497 1789-1803.

498 Passchier, C.W., Trouw, R.A.J., 2005. Microtectonics, 2nd, Revised and Enlarged ed. Springer-Verlag, 499 Berlin, $366 \mathrm{pp}$.

500 Petit, J.P., 1987. Criteria for the sense of movement on fault surfaces in brittle rocks. J. Struct. Geol. 9, 501 597-608.

502 Platt, J.P., Vissers, R.L.M., 1980. Extensional structures in anisotropic rocks. J. Struct. Geol. 2, 397-410.

503 Potyondy, D.O., Cundall, P.A., 2004. A bonded-particle model for rock. Int. J. Rock Mech. Min. Sci. 41, $504 \quad 1329-1364$.

505 Ramberg, H., 1975. Particle paths, displacement and progressive strain applicable to rocks.

506 Tectonophysics 28, 1-37. 
509 Rogowitz, A., Huet, B., Schneider, D., Grasemann, B., 2015. Influence of high strain rate deformation on 510 40Ar/39Ar mica ages from marble mylonites (Syros, Greece). Lithosphere 7, 535-540.

511 Samanta, S.K., Mandal, N., Chakraborty, C., 2002. Development of structures under the influence of 512 heterogeneous flow field around rigid inclusions: insights from theoretical and numerical models. Earth513 Sci. Rev. 58, 85-119.

514 Sander, B., 1950. Einführung in die Gefügekunde der geologischen Körper: Zweiter Teil: Die Korngefüge. 515 Springer-Verlag Berlin Heidelberg, Wien, 338 pp.

516 Scheffer, C., Vanderhaeghe, O., Lanari, P., Tarantola, A., Ponthus, L., Photiades, A., France, L., 2016. Syn517 to post-orogenic exhumation of metamorphic nappes: Structure and thermobarometry of the western 518 Attic-Cycladic metamorphic complex (Lavrion, Greece). J. Geodyn. 96, 174-193.

519 Schenk, O., Urai, J. L., van der Zee, W., 2007. Evolution of boudins under progressively decreasing pore pressure $A$ case study of pegmatites enclosed in marble deforming at high grade metamorphic conditions, Naxos, Greece. Am. J. Sci. 307, 1009-1033.

522 Schmalholz, S.M., Maeder, X., 2012. Pinch-and-swell structure and shear zones in viscoplastic layers. J. 523 Struct. Geol. 37, 75-88.

524 Schmid, D.W., Podladchikov, Y.Y., 2004. Are isolated stable rigid clasts in shear zones equivalent to 525 voids? Tectonophysics 384, 233-242.

526 Schmid, D.W., Podladchikov, Y.Y., 2005. Mantled porphyroclast gauges. Journal of Structural Geology 27, $527 \quad 571-585$.

528 Schöpfer, M.P.J., Childs, C., Manzocchi, T., Walsh, J.J., Nicol, A., Grasemann, B., 2017. The emergence of 529 asymmetric normal fault systems under symmetric boundary conditions. J. Struct. Geol. 104, 159-171.

530 Simpson, C., Schmid, S.M., 1983. An evaluation of criteria to deduce the sense of movement in sheared 531 rocks. Geol. Soc. Am. Bull. 94, 1281-1288.

532 Strömgård, K.E., 1973. Stress distribution during deformation of boudinage and pressure shadows.

533 Tectonophysics 16, 215-248.

534 Turner, F.J., Weiss, L.E., 1963. Structural analysis of metamorphic tectonites. McGraw-Hill, New York, 5351963.

536 Twiss, R.J., Moores, E.M., 2007. Structural Geology, 2nd Edition ed. W.H. Freeman and Company, New 537 York, $736 \mathrm{pp}$.

538 van der Pluijm, B., Marshak, S., 2004. Earth Structure - an Introduction to Structural Geology and 539 Tectonics, Second Edition ed. W. W. Norton \& Company, New York. 672 pp.

540 White, S.H., 1979. Large strain deformation: report on a Tectonic Studies Group discussion meeting held 541 at Imperial College, London on 14 November 1979. J. Struct. Geol. 1, 333-339. 
White, S.H., Bretan, P.G., Rutter, E.H., 1986. Fault zone reactivation: kinematics and mechanisms. Philos.

543 Trans. R. Soc. Lond. A-317, 81-97.

544 Wiesmayr, G., Grasemann, B., 2005. Sense and non-sense of shear in flanking structures with layer-

545 parallel shortening: implications for fault-related folds. J. Struct. Geol. 27, 249-264.

546 Xypolias, P., 2010. Vorticity analysis in shear zones: A review of methods and applications. J. Struct. Geol. $547 \quad 32,2072-2092$.

\section{Figure Captions}

550

551

552

Figure 1: Physical space and off-axis Mohr circle (De Paor and Means, 1984) of the deformation gradient tensor $(F)$ showing the eigenvectors of flow $\left(a_{1,2}\right)$, the angle $\alpha$ between the eigenvectors, the instantaneous stretching axes $\left(\mathrm{ISA}_{1,2}\right)$, and the maximum and minimum shear strain rate $\left(\dot{\gamma}_{1,2}\right)$. a) In simple shear $\left(W_{k}=1\right)$ the instantaneous shear and stretch of a finite-length slip surface is characterized by four different sectors, in which material lines are co-rotating: (+I) synthetic slip, shortening; (+II) antithetic slip, shortening; (+III) antithetic slip, stretching; (+IV) synthetic slip, stretching. b) In general shear $\left(W_{k}=0.8\right)$, two additional sectors are present and characterized by counter-rotation of material lines: (-I) synthetic slip, shortening; (-II) synthetic slip, stretching.

Figure 2: Selected mechanical models (for model details see Appendix A.1.) of an inviscid slip surface (red line) embedded in an incompressible viscous matrix showing the development of flanking structures visualized by passive marker lines (central grey layer and black thin solid lines). Insets in the right corners give the initial orientations of the slip surface. $\psi$ - initial orientation of the slip surface with respect to the shear direction; $F$ - deformation gradient tensor; $W_{k}$ - kinematic vorticity number. Half arrows indicate the modelled shear sense (dextral shear is positive): The central marker line exhibits a) synthetic extensional offset with normal drag, b) antithetic extensional offset with normal drag, c) contractional antithetic offset, and d) contractional synthetic offset.

Figure 3: Results of three discrete element method (DEM) models (for model details see Appendix A.2.) of the formation of fracture boudinage under coaxial strain boundary conditions comprising a brittle layer (with passive markers) embedded in a weak matrix at $10 \%$ extension. The polarity of the fracture system $P$ is the normalized sum of throw on left dipping (positive) and right dipping (negative) fractures. a) Dominant left-dipping interboudin surfaces. b) Almost no dominant dip direction. c) Dominant rightdipping interboudin surfaces. 
572 Figure 4: Finite elements method (FEM) models (for model details see Appendix A.3.) illustrating the 573 progressive deformation of domino boudins under a velocity boundary conditions close to dextral simple 574 shear $\left(W_{k}=0.9998\right)$. The initial aspect ratio of the boudins is three and the interboudin surfaces are 575 initially perpendicular to layering. $F$ is the exact imposed deformation gradient tensor, but since the 576 deformation is very close to simple shear the stages shown correspond approximately to a shear strain 577 of a) $y=5$, b) $\gamma=10$, and c) $y=15$. Note how the pronounced normal drag within the boudins along the 578 interboudin surfaces provides geometric similarities with asymmetric shear band boudinage forming 579 under the opposite shear sense. Only at the boudin edges, where the interboudin surfaces are in contact with the matrix, reverse drag develops (white arrows).

581 Figure 5: FEM models (for model details see Appendix A.3.) of sinistral simple shearing of an isolated 582 object with initial pinch-and-swell geometry progressively developing into a winged inclusion at shear 583 strains of a) $\gamma=0$, b) $\gamma=5$, c) $\gamma=10$, d) $y=15$, and e) $y=20$. The viscosity ratio between the object and 584 the matrix is 100 . The dotted black line is a central reference line initially parallel to the shear plane. 585 Note that after $\gamma=5$ and $y=20$ the winged inclusion resembles a $\sigma_{b}$-type clast with stair stepping 586 suggesting dextral shear sense.

Figure 6: Selected natural examples that are prone to be misinterpreted. a) Foliation boudinage in 588 Middle Cretaceous clay-rich limestones of the Nahr Umr Formation (Jabal Akhdar dome, Oman, $2583932 \mathrm{~N}, 518009 \mathrm{E}, \mathrm{UTM} 40)$. The shear sense is top-to-the NE and confirmed by other independent shear sense criteria (Grobe et al., in press). The central marker layer (black solid line) exhibits normal drag along antithetic cross-cutting elements (orange dotted lines) similar to the numerical models shown in Figure 4. Note that this structure could be easily misinterpreted as a shear band (foliation) boudinage yielding a top-to-the SW shear sense (picture courtesy of A. Grobe). b) Loose marble mylonite block collected from the Brenner Mesozoic of the Ötztal-Bundschuh Nappe System (Eastern Alps, Austria, $5216856 \mathrm{~N}, 682297 \mathrm{E}, \mathrm{UTM} 32)$. Although it is tempting to interpret the structure as an asymmetric boudinage with a top-to-the left shear sense, the sample was sheared top-to-the right, an interpretation consistent with large mica-fish within impure marble layers (orange arrows). Note the low displacement gradient along the interboudin surfaces characteristic for domino boudinage. c) Conglomeratic calcschists of the Glockner-Nappe System (Wasserfallwinkel, Großglockner, 327568E, 5218286N, UTM33). The deformed marble pebble exhibits a clear stair stepping suggesting a top-to-the SSE sense of shear. However, the structure developed during co-rotation of an elongated marble clast with wings slightly oblique to the main foliation. Note how the SC-fabric in the marble host rock is consistent with the overall top-to-the NNW sense of shear recorded elsewhere (Kurz et al., 1996). d) Flanking structures 
in an impure marble mylonite showing a noticeable change from reverse to normal drag of marker lines (black solid lines) along a secondary shear zone (red dotted line). The structure could be interpreted as an antithetic flanking fold or, alternatively and therefore consistent with an overall top to-the SW shear sense, as a synthetic shear band (Outzia area, N Kea, Greece, 4173029N, 265213E, UTM35). The latter interpretation is supported by high angle fractures rotated into the shear direction (white arrows).

DR 1: Movie of a mechanical model (for model details see Appendix A.1.) of an inviscid slip surface (red line) embedded in an incompressible viscous matrix showing the progressive development of flanking structures during ideal dextral simple shear. Initially the slip surface dips with $20^{\circ}$ into the shear direction. As the slip surface rotates into the shear direction, the offset on the slip surface is at first synthetic. However, after reaching a dip of $45^{\circ}$ into the shear direction, a shear sense reversal from synto antithetic occurs and reverse drag antithetic flanking folds with a pronounced hook-shape develop. Lastly, after a dip of $45^{\circ}$ against the shear direction is reached, a shear sense reversal on the slip surface from anti- to synthetic occurs.

\section{Appendix}

\section{A.1. Eshelby}

The modelling of flanking structures under general shear is performed using an approach similar to the method described in Kocher and Mancktelow (2005). For any given far field flow conditions and the current orientation of the cross-cutting element, the velocity field in the matrix is computed using the semi-analytical solution implemented in MATLAB and described in Exner and Dabrowski (2010) and Adamuszek and Dabrowski (2017). The cross-cutting element is modelled as a frictionless blade crack embedded in an isotropic linear viscous matrix and the solution is based on a reduced version of the external Eshelby solution (Eshelby, 1959), which accounts for both material incompressibility and an elliptic rather than an ellipsoidal inviscid inclusion. The developing structures are tracked with a set of initially horizontal material lines that are passively deformed by the evolving flow in the matrix. The lines' advection is computed using a highly accurate numerical solver, namely ode 45 as implemented in MATLAB (www.mathworks.com).

\section{A.2. DEM}

The Particle Flow Code in two dimensions (PFC-2D; Itasca Consulting Group, 2008), which implements the Distinct Element Method (DEM) for circular particles (Potyondy and Cundall, 2004), is used to model the formation of fracture boudinage developing in a central brittle layer embedded in a weak 
634 (cohesionless) matrix under symmetric (coaxial strain) boundary conditions. The three models shown in 635 Fig. 3 are a selection from a total of 32 model realizations with identical particle/bond properties, but 636 different random placement of particles. Different fracture system geometries and polarities are hence a 637 result of small differences in the initial conditions, a characteristic feature of chaotic behavior. For model 638 details, statistical analyses and discussion see Schöpfer et al. (2017).

\section{A.3. MILAMIN}

640 MILAMIN (Dabrowski et al., 2008), a MATLAB (www.mathworks.com) implementation of the finite 641 element method, is used to compute the flow field in and around the deforming boudins and the pinch642 and-swell objects presented in this work (Figs. 4 and 5, respectively). An unstructured triangular 643 computational mesh, which is frequently regenerated to maintain its quality and to accurately describe 644 the progressive structural development, is used (for details see Dabrowski and Grasemann, 2014; 645 Grasemann and Dabrowski, 2015). 
a) $D=\left[\begin{array}{llll}1 & 0.5 ; & 0 & 1\end{array}\right], W k=1$
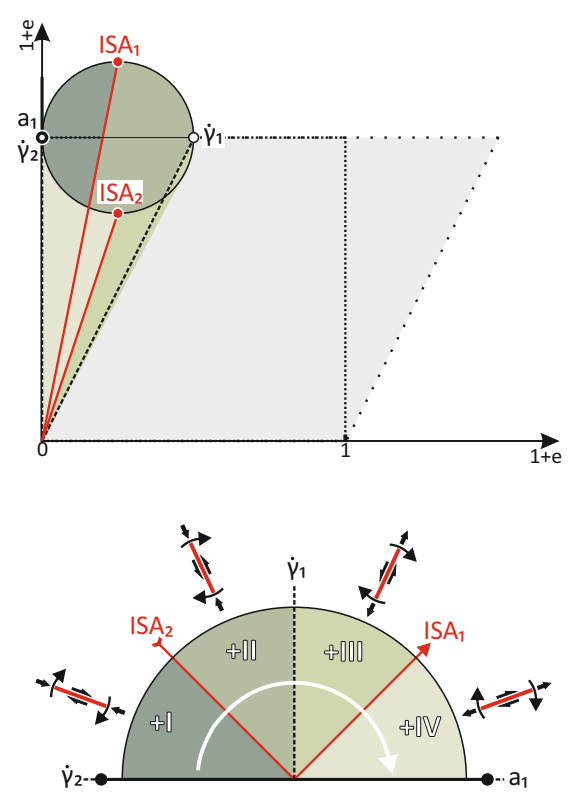

b) $D=\left[\begin{array}{llll}1.5 & 0.5 ; & 0 & 0.667\end{array}\right], W k=0.8$
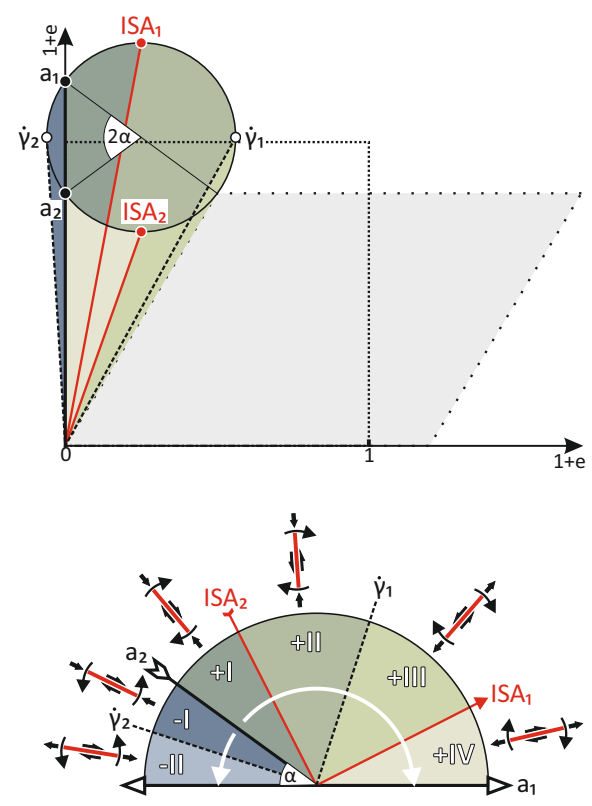

Fig. 1 - Grasemann et al JSG40 
a) $\psi=20^{\circ}, D=[1.2954-1.9535 ; 00.772], W_{k}=0.97$

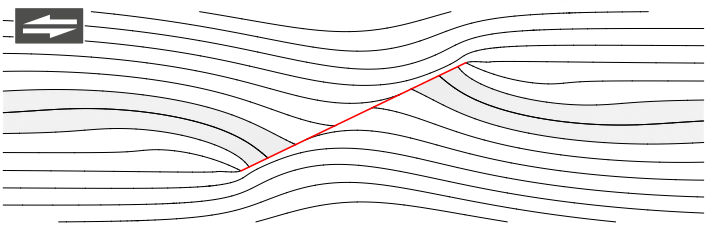

c) $\psi=45^{\circ}, D=[1-0.75 ; 01], W_{k}=1$

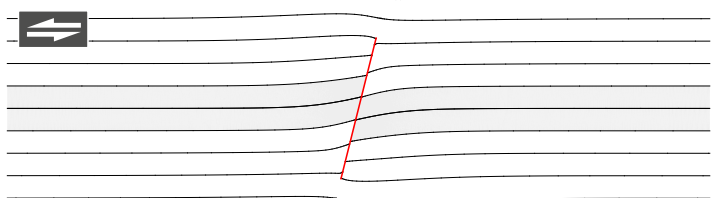

b) $\psi=20^{\circ}, D=\left[\begin{array}{llll}2.117 & 2.8486 ; 0 & 0.4724\end{array}\right], W_{k}=0.87$

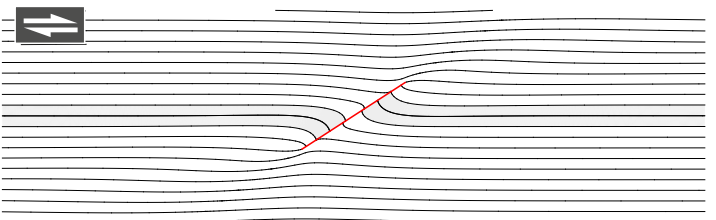

d) $\psi=135^{\circ}, D=\left[\begin{array}{lll}1 & 0.5 ; & 0\end{array}\right], W_{k}=1$

Fig. 2 - Grasemann et al JSG40 

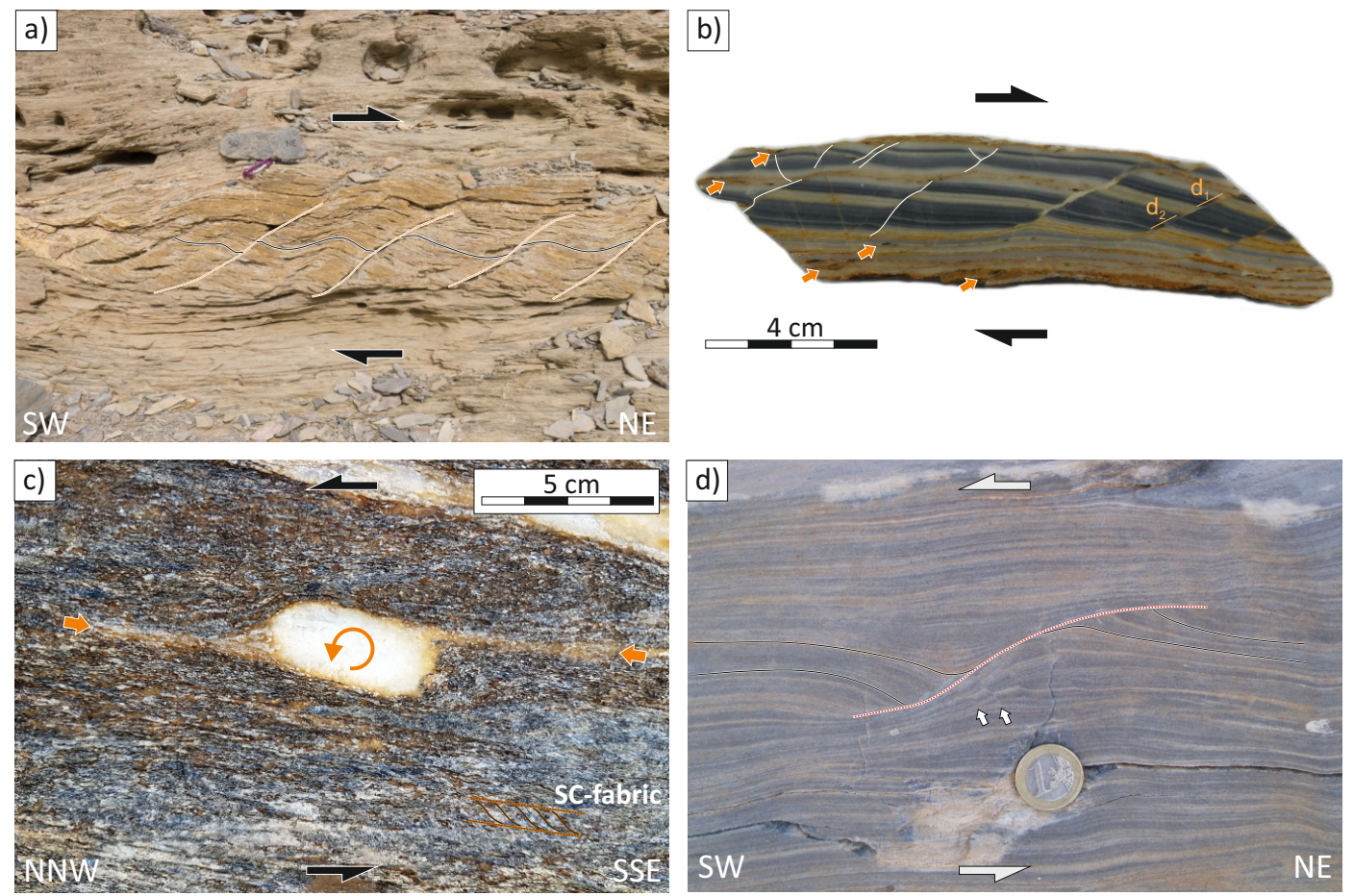

Fig. 6 - Grasemann et al JSG40 